\title{
Ambulatory arterial stiffness index, pulse pressure and pulse wave velocity in children and adolescents
}

\begin{abstract}
George S Stergiou ${ }^{1}$, Anastasios Kollias ${ }^{1}$, Periklis P Giovas ${ }^{1}$, John Papagiannis ${ }^{2}$ and Leonidas G Roussias ${ }^{1}$
Arterial stiffness, assessed by carotid-femoral pulse wave velocity (PWV) or indirectly by pulse pressure (PP) or ambulatory arterial stiffness index (AASI), is an independent predictor of cardiovascular disease in adults. However, in children limited evidence is available. This study investigated the usefulness of AASI and PP as indices of arterial stiffness in children and adolescents, by taking PWV as the reference method. Eighty-two children and adolescents (mean age $13.1 \pm 2.9$ years) had 24-h ambulatory blood pressure (ABP) monitoring, PWV measurement and echocardiography. Compared with normotensives, subjects with hypertension ( $n=16)$ had higher 24-h ABP, 24-h PP and PWV, but not AASI. 24-h, PP was strongly correlated with age, weight, height, 24-h systolic ABP, PWV, left ventricular mass (LVM), LVM index, stroke volume and inversely with 24-h heart rate. AASI was also correlated with weight, height, systolic ABP and LVM, yet these associations were weaker than those of PP, and no significant correlations were found with PWV or LVM index. Moreover, closer agreement of PWV was observed with 24-h PP (71\%, kappa 0.21$)$ than with 24-h AASI $(61 \%$, kappa -0.06) in detecting subjects at the top quartile of the respective distributions. In children and adolescents, 24-h PP compared with AASI appears to be more closely associated with: (i) arterial stiffness assessed by PWV; (ii) target organ damage assessed by LVM index; and (iii) the presence of essential hypertension. These data suggest that the usefulness of AASI as an index of arterial stiffness in the pediatric population is questionable. Hypertension Research (2010) 33, 1272-1277; doi:10.1038/hr.2010.178; published online 30 September 2010
\end{abstract}

Keywords: ambulatory arterial stiffness index; arterial stiffness; children; pulse pressure; pulse wave velocity

\section{INTRODUCTION}

Arterial wall stiffness assessed either directly by pulse wave velocity (PWV) or indirectly by pulse pressure (PP) appears to have an important role in the development of cardiovascular disease. ${ }^{1-8}$ Recently, the ambulatory arterial stiffness index (AASI) calculated on the basis of 24-h ambulatory blood pressure (ABP) recordings has been proposed as an easily derived and promising measure of arterial stiffness. ${ }^{9}$ Studies in normotensive and hypertensive adults have shown significant association of AASI values with established markers of arterial stiffness, such as PWV. ${ }^{10}$ Most importantly, recent studies showed a significant association of AASI with signs of target organ damage, as well as with non-fatal and fatal stroke and cardiovascular mortality, over and beyond PP and other risk factors. ${ }^{11-14}$

In the pediatric population, only few data are available with regard to the assessment of the arterial wall stiffness. Although no true gold standard has been established in this age range, the available evidence points to the PWV as the most widely studied, utilized and accepted method for the assessment of the arterial stiffness. ${ }^{15}$ On the contrary, evidence on the usefulness of AASI or PP in children is lacking. A single study reported increased values of AASI and PP in children with hypertension, which in most cases was secondary to chronic kidney disease. ${ }^{16}$ In addition, in a recent study, Raitakari et al. ${ }^{17}$ reported that PP in adolescence is associated with carotid intimamedia thickness in adulthood

Aiming to investigate the clinical usefulness of AASI in the pediatric population, this study evaluated AASI compared with PP in terms of their association with essential hypertension and PWV, as well as with target organ damage in children and adolescents.

\section{METHODS}

\section{Subjects}

This prospective study enrolled children and adolescents recruited in the Arsakeion study, a school-based cross-sectional study that evaluated home and office blood pressure (BP) measurements in 778 healthy children and adolescents aiming to determine the normal range of home BP in the pediatric population. ${ }^{18}$ The exclusion criteria were current or previous treatment with antihypertensive drugs, diabetes mellitus and renal, cardiac or other systemic disease, evidence of secondary hypertension, BP in the range of stage 2 hypertension in two consecutive clinic visits and any acute illness. Subjects participating in the Arsakeion study with office and/or home BP > 90th centile were invited to participate in this study that was conducted in a quiet room at school- and/or a hospital-based University Hypertension Center. ${ }^{18}$ Children and adolescents referred by individual physicians or other hospital clinics to the

${ }^{1}$ Third University Department of Medicine, Hypertension Center, Sotiria Hospital, University of Athens, Athens, Greece and ${ }^{2}$ Division of Pediatric Cardiology, Onassis Cardiac Surgery Center, Athens, Greece

Correspondence: Professor GS Stergiou, Third University Department of Medicine, Hypertension Center, Sotiria Hospital, University of Athens, 152, Mesogion Avenue, Athens 11527, Greece. 
Hypertension Center because of elevated BP were also recruited. Written informed consent was obtained from all participants and/or their parents and the protocol was approved by the hospital scientific committee.

A medical history was taken with the assistance of the participants' parents and anthropometric characteristics (weight, height, arm circumference) were recorded.

\section{BP measurements}

Participants had their BP assessed in the clinic and with 24-h ABP monitoring. Clinic BP measurements in at least two study visits performed 2-4 weeks apart were averaged to give a single BP per individual. Measurements were taken by physicians who fulfilled the British Hypertension Society Protocol criteria for agreement among observers in BP measurement. ${ }^{19}$ Triplicate BP measurements were performed during each clinic visit after $5 \mathrm{~min}$ sitting at rest and with at least $1 \mathrm{~min}$ between recordings, using standard mercury sphygmomanometers (inflatable bladder size $9 \times 18 \mathrm{~cm}^{2}, 12 \times 24 \mathrm{~cm}^{2}$ or $15 \times 35 \mathrm{~cm}^{2}$ according to the individuals' arm circumference). The average of the second and third BP measurement of each study visit was used in the analysis.

ABP was monitored on a usual school day using SpaceLabs 90207 oscillometric devices (SpaceLabs, Redmond, WA, USA; bladder size $9 \times 16 \mathrm{~cm}^{2}$, $12 \times 23 \mathrm{~cm}^{2}$ or $14 \times 30 \mathrm{~cm}^{2}$ as appropriate; measurements at 20 -min intervals for $24 \mathrm{~h}$ ). Subjects were instructed to remain still with their arm extended and relaxed during each measurement. Before each ABP monitoring session, the accuracy of each device was tested against a standard mercury sphygmomanometer by manual activation to ensure that there was no consistent difference of $>10 \mathrm{~mm} \mathrm{Hg}$ in the measured BP (three successive readings; $\mathrm{Y}$ connector). Daytime and nighttime periods were defined according to the individual's reported sleeping times. A non-dipping pattern was defined as a $<10 \%$ fall in systolic and/or diastolic BP during nighttime sleep as compared with awake measurements. Ambulatory hypertension was defined as average 24-h systolic and/or diastolic ABP $\geqslant 95$ th percentile. ${ }^{20,21}$ Twenty-four hour PP (systolicdiastolic 24-h $\mathrm{ABP}$ ) and mean arterial pressure (MAP; 24-h diastolic $\mathrm{ABP}+[0.4 \times 24-\mathrm{h} \mathrm{PP}])$ were calculated for each participant. ${ }^{22}$

\section{AASI derivatives estimation}

The regression slope of diastolic on systolic BP was computed for each individual on the basis of 24-h ABP readings. AASI was defined as one minus the respective regression slope. AASI was also computed from awake and asleep ABP readings (daytime and nighttime AASI, respectively). Symmetrical AASI was calculated using the formula 1-(1-AASI) $/ r$, with $r$ being the correlation coefficient between systolic and diastolic $\mathrm{ABP}^{23}$

\section{Echocardiography studies}

M-mode echocardiogram was performed by two observers experienced in pediatric echocardiography. Left ventricular mass (LVM) was determined from standard echocardiographic measurements according to the American Society of Echocardiography (average of three cardiac cycles) of the left ventricular enddiastolic dimension, the intraventricular septal thickness and the left ventricular posterior wall thickness, and was calculated using the formula: left ventricle mass $(\mathrm{g})=0.80[1.04$ (intraventricular septal thickness+left ventricular enddiastolic dimension+left ventricular posterior wall thickness)3-(left ventricular end-diastolic dimension)3]+0.6 (with echocardiographic measurements in centimeters) ${ }^{24}$ LVM was corrected by height in meters at the power of 2.7 to give LVM index (LVMI). ${ }^{25}$ The following calculations were used in the subsequent analyses: stroke volume $=$ end-diastolic volume - end-systolic volume; cardiac output $=$ stroke volume $\times$ heart rate; and total peripheral resistance $=\mathrm{MAP} /$ cardiac output.

\section{Carotid-femoral pulse wave analysis}

Carotid-femoral (aortic) PWV was measured in the supine position automatically using the Complior apparatus (Colson, Garges-les-Gonesse, Paris, France) as described previously. ${ }^{26}$ Its determination is based on the simultaneous recording of the pulse wave in the common carotid and femoral arteries by two transducers and is calculated as the distance separating the two transducers divided by the time delay between the onset (foot) of the two recorded waves.

\section{Statistical analysis}

Subjects with less than 11 valid awake or 7 asleep ABP readings were excluded. The ABP data and additional recorded information from the report files generated by the ABP monitor device were batch imported and organized in a relational database (Microsoft Access 2000; Microsoft Corp., Redmond, WA, USA) using a Visual Basic program. This program, designed by LGR for statistical analysis of ABP-derived data, reads the ASCII text files generated by the ABP monitor and performs multiple data procedures and analyses. Systolic ABP readings $<50$ or $>250 \mathrm{~mm} \mathrm{Hg} \mathrm{BP}$ or diastolic $<30$ or $>150 \mathrm{~mm} \mathrm{Hg}$ were excluded, as were ambulatory measurements flagged by the software of the monitors as being technically erroneous. Ambulatory readings taken $<20 \mathrm{~min}$ after the monitor had been attached to subjects were also excluded because these had been taken in the clinic.

Student's $t$-tests were used for the comparison of the quantitative variables between groups and $\chi^{2}$ for categorical variables. Analysis of covariance (ANCOVA) was used when adjustment for covariates was necessary. Pearson bivariate correlations were performed to explore the relationship between quantitative variables. Correlation coefficients were compared using the $z$-statistic. The agreement between PWV, AASI and PP in detecting subjects at the top quartile of their respective distributions was estimated using the kappa statistic. Forced entry and stepwise multiple regression analyses were performed to identify variables that affect PWV, AASI and PP values. Tolerance and variance inflation factor were used for the assessment of potential multicollinearity in the multiple regression models. Results are expressed as mean values with s.d. A probability value $P<0.05$ was considered statistically significant. Statistical analysis was performed using the Statistical Package for Social Sciences software (SPSS release 13.0; SPSS, Chicago, IL, USA).

\section{RESULTS}

\section{Participants' characteristics}

Eighty-four children fulfilled the inclusion criteria and were recruited in the study. Two children were excluded owing to inadequate number of valid ABP readings. A total of 82 children and adolescents, who had valid 24-h ABP recordings and PWV measurements and 50 of them who also had echocardiography, were included in the analysis. Sixteen children had average 24-h systolic and/or diastolic ABP $\geqslant 95$ th percentile and were classified as hypertensive. The main anthropometric characteristics of the study participants were: age, $13.1 \pm 2.9$ years; height, $162.4 \pm 17.6 \mathrm{~cm}$; weight, $60.6 \pm 21.2 \mathrm{~kg}$; body mass index (BMI), $22.2 \pm 4.6 \mathrm{~kg} \mathrm{~m}^{-2}$; and $66 \%$ males. The hemodynamic characteristics are shown in Table 1 . The average number of $24-\mathrm{h} \mathrm{ABP}$

\section{Table 1 Participants' BP levels and indices of arterial stiffness (mean \pm s.d.)}

\section{Characteristics}

Office systolic BP ( $\mathrm{mm} \mathrm{Hg})$

$118.4 \pm 13.1$

Office diastolic BP $(\mathrm{mm} \mathrm{Hg})$

$69.3 \pm 11.6$

24-h systolic BP $(\mathrm{mm} \mathrm{Hg})$

$119.1 \pm 12.2$

24-h diastolic BP $(\mathrm{mm} \mathrm{Hg})$

$66.6 \pm 6.3$

24-h nocturnal systolic BP reduction (\%)

13.1

24-h nocturnal diastolic BP reduction (\%)

20.7

24-h pulse pressure ( $\mathrm{mm} \mathrm{Hg}$ )

$52.5 \pm 9.3$

24-h pulse rate (b.p.m.)

$77.8 \pm 9.5$

24-h AASI

$0.35 \pm 0.18$

Daytime AASI

$0.53 \pm 0.21$

Nighttime AAS

$0.50 \pm 0.22$

Symmetrical AASI

$0.09 \pm 0.17$

Pulse wave velocity $\left(\mathrm{m} \mathrm{s}^{-1}\right)$

$6.5 \pm 1.7$

Left ventricular mass (g)

$115.1 \pm 42.2$

Left ventricular mass index $\left(\mathrm{g} \mathrm{m}^{-2.7}\right)$

$29.0 \pm 6.5$ 
Table 2 Comparison of the anthropometric and hemodynamic variables between normotensive and hypertensive participants

\begin{tabular}{lccc}
\hline & $\begin{array}{c}\text { Normotensives } \\
(\mathrm{n}=66)\end{array}$ & $\begin{array}{c}\text { Hypertensives } \\
(\mathrm{n}=16)\end{array}$ & P-value \\
\hline Age (years) & $12.8 \pm 3$ & $14.2 \pm 2.8$ & 0.08 \\
Males (\%) & $40(61 \%)$ & $14(88 \%)$ & 0.08 \\
Height (cm) & $160.7 \pm 17.7$ & $169.4 \pm 15.4$ & 0.08 \\
Weight (kg) & $58.3 \pm 21.2$ & $69.8 \pm 18.8$ & 0.05 \\
Body mass index (kg m $\left.{ }^{-2}\right)$ & $21.8 \pm 4.8$ & $23.9 \pm 3.7$ & 0.11 \\
24-h systolic BP (mm Hg) & $115.1 \pm 8.9$ & $135.6 \pm 9.9$ & $<0.001$ \\
24-h diastolic BP (mm Hg) & $64.7 \pm 4.5$ & $74.3 \pm 6.8$ & $<0.001$ \\
24-h pulse pressure (mm Hg) & $50.4 \pm 8.3$ & $61.3 \pm 8.4$ & $<0.001$ \\
24-h pulse rate (b.p.m.) & $77.9 \pm 9.2$ & $77.3 \pm 10.9$ & 0.81 \\
24-h AASI & $0.34 \pm 0.18$ & $0.36 \pm 0.19$ & 0.80 \\
Daytime AASI & $0.52 \pm 0.20$ & $0.56 \pm 0.25$ & 0.48 \\
Nighttime AASI & $0.51 \pm 0.22$ & $0.49 \pm 0.20$ & 0.70 \\
Symmetrical AASI & $0.09 \pm 0.16$ & $0.08 \pm 0.19$ & 0.74 \\
Pulse wave velocity (m s $\left.{ }^{-1}\right)$ & $6.3 \pm 1.7$ & $7.4 \pm 1.2$ & 0.02 \\
Left ventricular mass $(\mathrm{g})$ & $110.0 \pm 36.0$ & $129.6 \pm 55.6$ & 0.15 \\
Left ventricular mass Index $\left(\mathrm{gm}^{-2.7}\right)$ & $28.6 \pm 5.4$ & $30.3 \pm 9$ & 0.43 \\
\hline
\end{tabular}

Abbreviations: AASI, ambulatory arterial stiffness index; BP, blood pressure.

readings analyzed was $63.3 \pm 7$ (38.6 \pm 6.4 for daytime, range: $20-53$ and $25 \pm 4.3$ for nighttime, range: $8-36$ ).

\section{Subgroups comparisons}

Hypertensive subjects had higher 24-h systolic and diastolic ABP, 24-h PP and PWV, but not AASI, compared with normotensives (Table 2). The difference remained significant for 24-h systolic and diastolic ABP, and 24-h PP after adjustment for age, gender and BMI (ANCOVA, $P<0.05$ for all comparisons), whereas it was attenuated for PWV (ANCOVA, $P=0.15$ ).

\section{Correlations and multivariate analyses}

Twenty-four hour systolic BP was correlated with PWV $(r=0.35$, $P=0.001)$ and LVM $(r=0.59, P<0.001)$. The associations of 24 -h AASI and PP with several anthropometric and hemodynamic variables are shown in Table 3. In particular, 24-h PP was strongly correlated with age, weight, height, BMI, systolic ABP, PWV, LVM and LVMI, stroke volume and inversely with 24 -h heart rate (Table 3 ). On the other hand, AASI was correlated with weight, height, BMI, systolic $\mathrm{ABP}, \mathrm{LVM}$ and inversely with diastolic ABP, yet the strength of these associations was consistently weaker than those of PP (Table 3). The correlation among the arterial stiffness indices is shown in Figure 1. Clinic systolic BP at the time of PWV measurement was also correlated with PWV $(r=0.28)$, AASI $(r=0.25)$, 24-h PP $(r=0.67)$ and LVM $(r=0.49)$ (all $P<0.05)$.

Forced entry multivariate regression analysis was performed to identify independent associations of PWV, PP and AASI. Age, gender, BMI, heart rate, 24-h systolic BP and MAP dipping (\%) were included as independent variables and PWV or PP or AASI as dependent variables. $\mathrm{PWV}$ was independently $(P<0.05)$ associated with BMI $(0.14 \pm 0.04$, beta \pm s.e. $), \mathrm{PP}$ with systolic $\mathrm{ABP}(0.59 \pm 0.05)$, heart rate $(-0.24 \pm 0.07)$ and BMI $(0.40 \pm 0.12)$, and AASI with BMI $(0.02 \pm 0.004)$ and MAP dipping $(-0.01 \pm 0.003)$. In order to identify the main determinants that best explain the variance of the arterial stiffness indices, a stepwise multiple regression analysis was performed with the same variables (Table 4). The covariates entered the model
Table 3 Bivariate correlation coefficients of several demographic and hemodynamic variables with AASI and PP

\begin{tabular}{lccc}
\hline Variables & $24-h$ AASI & $24-h P P$ & P-value (AASI vs. PP) \\
\hline 24-h AASI & - & $0.50^{\ddagger}$ & - \\
Age & 0.13 & $0.53^{\ddagger}$ & $\dagger$ \\
Height & $0.24^{*}$ & $0.66^{\ddagger}$ & $\ddagger$ \\
Weight & $0.32^{\dagger}$ & $0.64^{\ddagger}$ & $\dagger$ \\
Body mass index & $0.30^{\dagger}$ & $0.42^{\ddagger}$ & $\mathrm{NS}$ \\
24-h systolic BP & $0.26^{*}$ & $0.86^{\ddagger}$ & $\ddagger$ \\
24-h diastolic BP & $-0.23^{*}$ & 0.19 & $\dagger$ \\
24-h heart rate & -0.20 & $-0.39^{\ddagger}$ & $\mathrm{NS}$ \\
Pulse wave velocity & -0.01 & $0.36^{\dagger}$ & $*$ \\
Left ventricular mass & $0.37^{\dagger}$ & $0.68^{\ddagger}$ & $\mathrm{NS}$ \\
Left ventricular mass index & 0.24 & $0.33^{*}$ & $\mathrm{NS}$ \\
Stroke volume & 0.17 & $0.36^{*}$ & $\mathrm{NS}$ \\
Peripheral resistance & -0.03 & 0.12 &
\end{tabular}

Abbreviations: AASI, ambulatory arterial stiffness index; $\mathrm{BP}$, blood pressure; PP, pulse pressure NS, non-significant.

${ }^{*} P<0.05$.

$P \leqslant 0.01$.

$\ddagger \leqslant 0.001$.

only if $P$-value was $<0.05$. This analysis showed that the three indices of arterial wall stiffness did not share exactly the same predictors; PWV was predicted by BMI and systolic ABP, PP was predicted by BMI, systolic ABP and heart rate, and AASI was mainly explained by BMI, gender and MAP dipping (Table 4). It should be noted that in all the above models, the lowest observed tolerance was 0.47 and the highest variance inflation factor was 2.45 , which ensure the lack of multicollinearity between the used covariates.

\section{Diagnostic agreement analysis}

Closer agreement was observed between PWV and PP (agreement 70.7\%, kappa 0.21) compared with that between PWV and 24-h AASI (agreement 61\%, kappa -0.06) in detecting subjects at the top quartile of the respective distributions. However, a satisfactory agreement was observed between 24-h AASI and PP (82.9\%, kappa 0.54).

\section{DISCUSSION}

This study assessed the relationship of the recently proposed marker of arterial stiffness AASI with 24-h ambulatory PP and PWV in children and adolescents referred to a BP clinic. The main findings are: (i) hypertensive children compared with normotensive children had higher PWV and 24-h PP, but not AASI; (ii) 24-h PP appeared to be more closely associated with anthropometric and hemodynamic indices, including PWV as compared with AASI; (iii) the agreement with PWV in detecting subjects at the top quartile of the respective distributions was higher for 24-h PP compared with AASI; and (iv) different covariates appeared to predict PWV, 24-h PP and AASI.

Although studies in adults have established that arterial wall stiffness assessed by PWV, PP and recently AASI plays an important role in predicting cardiovascular disease, such data on children are not available. A limited number of studies have reported higher PWV values in pediatric patients with type 1 diabetes, ${ }^{27,28}$ neurofibromatosis, ${ }^{29}$ snoring, ${ }^{30}$ Kawasaki disease, ${ }^{31}$ polyarteritis nodosa ${ }^{32}$ and coarctation of the aorta after surgical repair. ${ }^{33}$ Most of these studies have control groups of varying mean ages and with numbers ranging from 28 to 155 subjects. ${ }^{15}$ Recently, PWV was evaluated in populations of healthy children and adolescents, with gender and racial 

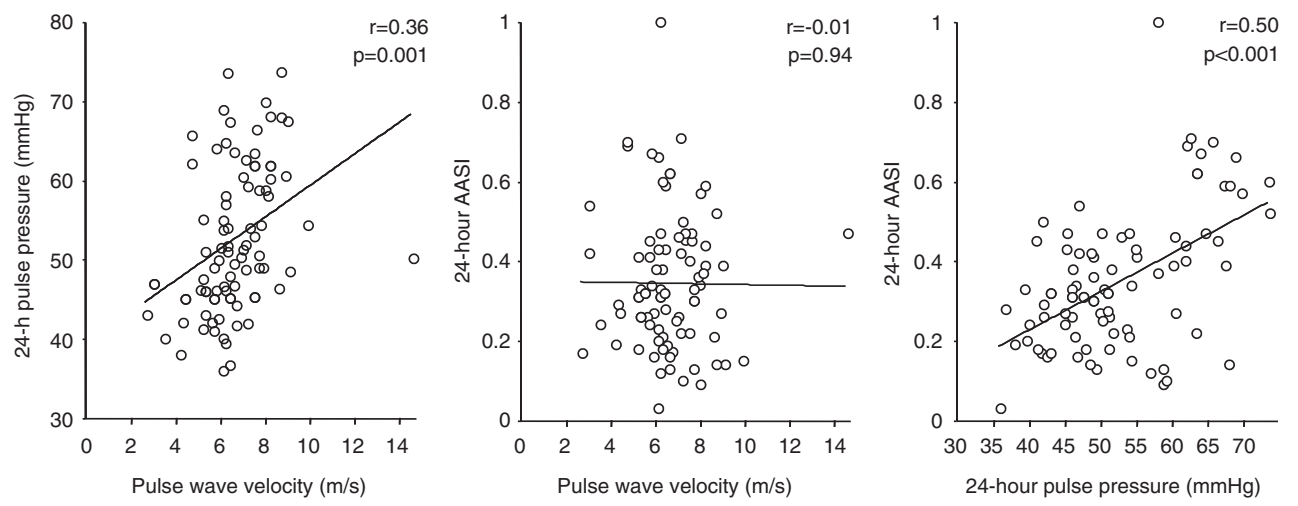

Figure 1 Association among pulse wave velocity (PWV), 24-h ambulatory pulse pressure (PP) and ambulatory arterial stiffness index (AASI). PWV is associated with 24-h PP, but not with AASI. Both 24-h PP and AASI are indirect indices of arterial stiffness derived from ambulatory blood pressure (BP) monitoring, which could explain their correlation. On the other hand, PWV is a direct marker of arterial stiffness, mainly determined by BP levels. PP is highly correlated with systolic BP levels by its definition, whereas AASI is mainly determined by nocturnal dipping. This could, at least in part, explain the correlation between PWV only with PP.

Table 4 Independent determinants of the arterial stiffness indices estimated by stepwise multiple linear regression analysis (results as mean \pm s.e.)

\begin{tabular}{lccc}
\hline Covariates & $\begin{array}{c}P W V \\
\left(\mathrm{R}^{2}=0.28\right)\end{array}$ & $\begin{array}{c}24-h P P \\
\left(\mathrm{R}^{2}=0.80\right)\end{array}$ & $\begin{array}{c}24-h \text { AASI } \\
\left(\mathrm{R}^{2}=0.28\right)\end{array}$ \\
\hline Age & - & - & - \\
Gender & - & - & $-0.09 \pm 0.04^{\dagger}$ \\
Body mass index & $0.15 \pm 0.04^{\dagger}$ & $0.29 \pm 0.11^{\dagger}$ & $0.01 \pm 0.004^{\dagger}$ \\
24-h systolic BP & $0.03 \pm 0.01^{*}$ & $0.59 \pm 0.04^{\dagger}$ & - \\
MAP dipping (\%) & - & - & $-0.01 \pm 0.003^{\dagger}$ \\
24-h heart rate & - & $-0.20 \pm 0.05^{\dagger}$ & - \\
\hline
\end{tabular}

Abbreviations: AASI, ambulatory arterial stiffness index; MAP, mean arterial pressure; PP, pulse pressure; PWV, pulse wave velocity.

${ }^{*} P<0.05$.

$P \leqslant 0.01$

differences being present, although the findings concerning correlations with anthropometric indices were inconclusive. ${ }^{34-37}$ In particular, Niboshi et al. ${ }^{35}$ measured brachial-ankle PWV in 970 healthy Japanese children with mean values of 9.97 and $9.47 \mathrm{~m} \mathrm{~s}^{-1}$ for boys and girls, respectively, and set up normal percentile values on the basis of age and gender. In this study, age, BP and heart rate were significant determinants of PWV, whereas BMI had no correlation with PWV. ${ }^{35}$ Collins et al. ${ }^{34}$ also determined brachial-ankle PWV in 205 US normotensive adolescents aged 15.9 years old and reported a mean value of brachial-ankle PWV at $10.7 \mathrm{~m} \mathrm{~s}^{-1}$, which was higher compared with that of the Japanese cohort. Collins et al. ${ }^{34}$ also reported significant correlations of PWV with age, gender and ethnicity, but not with BMI. On the other hand, Im et al. ${ }^{36}$ and Sakuragi et al. ${ }^{37}$ showed significant associations of PWV with BP and BMI in a large cohort of Korean and Australian young subjects, respectively. The study of Sakuragi et $a l^{37}$ which was performed in 573 children aged 10.1 years old, is the only one reporting values of carotid-femoral PWV $\left(4.4 \mathrm{~m} \mathrm{~s}^{-1}\right)$. In conclusion, there are no reference values of PWV in children and adolescents at least at an international level. Determinants of this marker also are not well established. These facts account for the reluctance in the use of PWV in clinical practice in children. However, it should be noted the PWV is the most studied, reproducible, accepted and utilized method for the assessment of arterial wall stiffness in children, at present. ${ }^{15}$
Several studies in the adults have shown PP to be a useful indirect marker of arterial stiffness and an independent risk factor of cardiovascular morbidity and mortality. ${ }^{6-8}$ Moreover, 24-h ABP monitoring has been shown to provide the most reproducible PP values. ${ }^{38}$ AASI derived from 24-h ambulatory BP monitoring has been recently proposed as an easily applicable measure of arterial stiffness, which predicts the incidence of cardiovascular events over and beyond PP. ${ }^{11-14}$ However, none of these measures has been investigated in children. A single study by Simonetti et al. ${ }^{16}$ showed higher values of both PP and AASI in hypertensive children compared with healthy children. In contrast, in this study, although PP was higher in hypertensive children than in normotensive children, AASI did not differ. An important difference between this study and that by Simonetti et al. ${ }^{16}$ is that in the latter most of the hypertensive children had renal disease, whereas in this study secondary hypertension was excluded.

In this study, PP was closely associated with PWV and LVMI, whereas no such associations were found for AASI. Furthermore, the associations of BP and anthropometric values with PP were stronger than with AASI. Finally, when the agreement of the studied indices in detecting subjects at the top quartile of the respective distributions was assessed-a criterion with practical relevance-fair agreement was found between PP and PWV, but not between AASI and PWV. These findings suggest that in children PP is a superior index compared with AASI, given its closer relationship and agreement with a direct marker of arterial wall stiffness (PWV) and with target organ damage (LVMI).

Previous studies in adults have questioned the clinical relevance of AASI and showed superiority of PP in predicting arterial stiffness, target organ damage and cardiovascular events. In particular, Schillaci et al. $^{39}$ reported a significant bivariate relation between AASI and LVMI, as well as with PWV in untreated hypertensive adults; however, both relationships were diminished after adjustment for other parameters. Likewise, Jerrard-Dunne et al. ${ }^{40}$ found significant relationships of AASI with PWV or augmentation index in hypertensives, which were lost after adjustment for age. Furthermore, Muxfeldt et al. ${ }^{41}$ showed that in patients with resistant hypertension, 24-h PP was more closely associated with arterial stiffness (PWV) than AASI. Moreover, it has been reported that in young adults with type 1 diabetes, AASI and PP were higher in the presence of microalbuminuria; however, the standardized coefficients tended to be higher for PP. ${ }^{42}$ Finally, Dolan et al. ${ }^{13}$ showed that although both AASI and PP 
predicted cardiovascular mortality, PP was a stronger predictor for cardiac events. It should be noted that the studies so far show that AASI may have some interest in studying large groups, yet the usefulness of clinical application of AASI in the assessment of individuals remains unproved. The aforementioned studies are in line with the findings of this study suggesting that, as it is the case in the adults, in children and adolescents where the evidence is scarce, the clinical significance of AASI in relation to the presence of subclinical end-organ damage is uncertain.

A tricky finding of this study is that PWV, PP and AASI appeared to be determined by different covariates. More specifically, in multivariate regression analysis, $\mathrm{PWV}$ was predicted by BMI and systolic ABP, 24-h PP by BMI, systolic ABP and heart rate and AASI by BMI, gender and MAP dipping. However, the fact that PWV is a direct estimate of arterial stiffness, whereas PP and AASI are rather surrogate markers should not be neglected. Furthermore, the dependence of PWV and PP on systolic ABP (which is dependent on cardiac output and arterial stiffness) is important since it underlines the significance of both arterial properties and cardiac function characteristics (contractility and heart rate) in the determination of these indices. Indeed, in this analysis PP was correlated with stroke volume and inversely with heart rate. On the contrary, AASI is dependent on the constant relationship of systolic and diastolic BP, defined mainly by the arterial wall properties, which could explain the negative correlation only with MAP dipping (dipping status is associated with a higher correlation of systolic and diastolic $\mathrm{BP}^{23}$ ). Previous reports have confirmed this inverse relation between nocturnal dipping and AASI values. ${ }^{23,39,43,44}$ It should be taken into account that AASI and PP are calculated from the same data (24-h ABP recordings). This might explain, at least in part, the association between these two parameters. However, the fact that PP is related to PWV, whereas AASI is not, suggests that caution is needed in the use of AASI as a marker of arterial stiffness in children.

The findings of this study are similar to those of Muxfeldt et al. ${ }^{41}$ In particular, Muxteldt et al. ${ }^{41}$ compared the association of PWV with 24-h PP and AASI in 391 patients with resistant hypertension. The correlation of PWV with PP was stronger than with AASI, and when adjusted for other covariates, the latter became non-significant. ${ }^{41}$ Moreover, in multiple regression analysis, PWV and PP shared the same independent associations (age, gender, diabetes, 24-h MAP and nocturnal diastolic ABP reduction), whereas AASI was associated only with age, diabetes and nocturnal diastolic ABP reduction. ${ }^{41}$ Similarly, in this study, PWV was correlated with PP, but not with AASI. Furthermore, PWV and PP shared BMI and systolic ABP as their predictors, whereas AASI was determined by MAP dipping, but not systolic ABP levels. It should be noted, however, that children differ from the study population of Muxfeldt (hypertensive subjects aged 64 years old with other cardiovascular risk factors). In children, the arterial system is more elastic, a fact that explains the absence of age as a determinant of the arterial stiffness indices and justifies the dependence of PWV on BP levels. Moreover, anthropometric variables are expected to affect arterial stiffness in childhood. As 24-h PP by its definition is highly correlated with systolic ABP, the superiority of 24-h PP over AASI in terms of their association with PWV (which is mainly determined by BP levels) seems to be apparent. However, studies in adults have shown that AASI is correlated with PWV, although this association is weakened when adjusted for other covariates. ${ }^{10,39-41}$ Moreover, 24-h PP and PWV may be strongly inter-related, but do not share the same hemodynamic physiology. $\mathrm{PP}$ at the brachial artery increases with increasing arterial stiffness owing to the faster return of the reflected waves, which superimpose on the forward wave, but it is also determined by other factors such as ventricular ejection and heart rate, as well as the amplification phenomenon. ${ }^{45}$

Although 24-h ABP monitoring is a highly reliable method for BP assessment in terms of reproducibility in adults, AASI presents only moderate reproducibility. ${ }^{46}$ This is, at least in part, attributed to the fact that AASI depends on nocturnal dipping and it is known that night ABP pattern has only a limited reproducibility. ${ }^{46}$ In children and adolescents, ABP monitoring is characterized by high reproducibility. ${ }^{47-49}$ In particular, Lurbe et al. ${ }^{47}$ reported test-retest correlation coefficients $0.76 / 0.68$ for 24 -h systolic/diastolic ABP, whereas in the study of Stergiou et al., ${ }^{49}$ the respective values were $0.87 / 0.84$. However, in these studies a poor reproducibility of the parameters of the diurnal BP variation was reported. ${ }^{48,49}$ More specifically, the reproducibility of the parameters of the diurnal ABP curve tended to be less than that of the ABP level, whereas in the study of Stergiou et al., ${ }^{49}$ the correlations related to the diurnal BP variation (day/nighttime ABP difference and ratio) were not significant. ${ }^{48}$ Although there are no data on AASI reproducibility in children, the limited reproducibility of diurnal ABP variation is expected to have a negative effect on it, as it is the case in the adults.

These findings should be interpreted in light of some limitations. First, the number of participants is relatively small. However, the persistence of statistical significance after adjustment for several covariates is reassuring for the validity of the findings. Second, the cross-sectional nature of the study does not permit conclusions about causal mechanisms or the cause-effect relationship between the examined indices and target organ damage.

In conclusion, this study provides the first evidence that in children 24-h PP compared with AASI appears to be more closely associated with: (i) arterial stiffness assessed by PWV; (ii) target organ damage assessed by LVMI; and (iii) the presence of essential hypertension. In the absence of outcome studies, these results question the usefulness of AASI as a marker of arterial stiffness in the pediatric population.

\section{CONFLICT OF INTEREST}

The authors declare no conflict of interest.

\section{ACKNOWLEDGEMENTS}

This work was financially supported by University of Athens grant (Kapodistrias Program 2005 and 2006, Grant No. 70/4/8107). Home blood pressure monitors were provided by G Leoussis IS, Athens, Greece.

1 Laurent S, Boutouyrie P, Asmar R, Gautier I, Laloux B, Guize L, Ducimetiere P, Benetos A. Aortic stiffness is an independent predictor of all-cause and cardiovascular mortality in hypertensive patients. Hypertension 2001; 37: 1236-1241.

2 Boutouyrie P, Tropeano Al, Asmar R, Gautier I, Benetos A, Lacolley P, Laurent S. Aortic stiffness is an independent predictor of primary coronary events in hypertensive patients: a longitudinal study. Hypertension 2002; 39: 10-15.

3 Laurent S, Katsahian S, Fassot C, Tropeano AI, Gautier I, Laloux B, Boutouyrie P. Aortic stiffness is an independent predictor of fatal stroke in essential hypertension. Stroke 2003; 34: 1203-1206

4 Sutton-Tyrrell K, Najjar SS, Boudreau RM, Venkitachalam L, Kupelian V, Simonsick EM, Havlik R, Lakatta EG, Spurgeon H, Kritchevsky S, Pahor M, Bauer D, Newman A. Elevated aortic pulse wave velocity, a marker of arterial stiffness, predicts cardiovascular events in well-functioning older adults. Circulation 2005; 111: 3384-3390.

5 Willum-Hansen T, Staessen JA, Torp-Pedersen C, Rasmussen S, Thijs L, Ibsen H, Jeppesen J. Prognostic value of aortic pulse wave velocity as index of arterial stiffness in the general population. Circulation 2006; 113: 664-670.

6 Benetos A, Zureik M, Morcet J, Thomas F, Bean K, Safar M, Ducimetiere P, Guize L. A decrease in diastolic blood pressure combined with an increase in systolic blood pressure is associated with a higher cardiovascular mortality in men. J Am Coll Cardiol 2000; 35: 673-680.

7 Franklin SS, Khan SA, Wong ND, Larson MG, Levy D. Is pulse pressure useful in predicting risk for coronary heart disease? The Framingham Heart Study. Circulation 1999; 100: 354-360. 
8 Verdecchia P, Schillaci G, Borgioni C, Ciucci A, Pede S, Porcellati C. Ambulatory pulse pressure: a potent predictor of total cardiovascular risk in hypertension. Hypertension 1998; 32: 983-988.

9 Dolan E, Li Y, Thijs L, McCormack P, Staessen JA, O'Brien E, Stanton A. Ambulatory arterial stiffness index: rationale and methodology. Blood Press Monit 2006; 11: 103-105.

10 Li Y, Wang JG, Dolan E, Gao PJ, Guo HF, Nawrot T, Stanton AV, Zhu DL, O'Brien E, Staessen JA. Ambulatory arterial stiffness index derived from 24-h ambulatory blood pressure monitoring. Hypertension 2006; 47: 359-364.

11 Li Y, Dolan E, Wang JG, Thijs L, Zhu DL, Staessen JA, O'Brien E, Stanton A. Ambulatory arterial stiffness index: determinants and outcome. Blood Press Monit 2006; 11: 107-110.

12 Hansen TW, Staessen JA, Torp-Pedersen C, Rasmussen S, Li Y, Dolan E, Thijs L, Wang JG, O'Brien E, Ibsen H, Jeppesen J. Ambulatory arterial stiffness index predicts stroke in a general population. J Hypertens 2006; 24: 2247-2253.

13 Dolan E, Thijs L, Li Y, Atkins N, McCormack P, McClory S, O’Brien E, Staessen JA, Stanton AV. Ambulatory arterial stiffness index as a predictor of cardiovascular mortality in the Dublin Outcome Study. Hypertension 2006; 47: 365-370.

14 Kikuya M, Staessen JA, Ohkubo T, Thijs L, Metoki H, Asayama K, Obara T, Inoue R, Li Y, Dolan E, Hoshi H, Hashimoto J, Totsune K, Satoh H, Wang JG, O'Brien E, Imai Y. Ambulatory arterial stiffness index and 24-h ambulatory pulse pressure as predictors of mortality in Ohasama, Japan. Stroke 2007; 38: 1161-1166.

15 Urbina EM, Williams RV, Alpert BS, Collins RT, Daniels SR, Hayman L, Jacobson M, Mahoney L, Mietus-Snyder M, Rocchini A, Steinberger J, McCrindle B, American Heart Association Atherosclerosis Hypertension Obesity in Youth Committee of the Council on Cardiovascular Disease in the Young. Noninvasive assessment of subclinical atherosclerosis in children and adolescents: recommendations for standard assessment for clinical research: a scientific statement from the American Heart Association. Hypertension 2009; 54: 919-950.

16 Simonetti GD, Von Vigier RO, Wuhl E, Mohaupt MG. Ambulatory arterial stiffness index is increased in hypertensive childhood disease. Pediatr Res 2008; 64: 303-307.

17 Raitakari OT, Juonala M, Taittonen L, Jula A, Laitinen T, Kahonen M, Viikari JS. Pulse pressure in youth and carotid intima-media thickness in adulthood: the cardiovascular risk in young Finns study. Stroke 2009; 40: 1519-1521.

18 Stergiou GS, Yiannes NG, Rarra VC, Panagiotakos DB. Home blood pressure normalcy in children and adolescents: the Arsakeion School study. J Hypertens 2007; 25: 13751379.

19 O'Brien E, Petrie J, Littler W, de Swiet M, Padfield PL, Altman DG, Bland M, Coats A, Atkins N. An outline of the revised British Hypertension Society protocol for the evaluation of blood pressure measuring devices. J Hypertens 1993; 11: 677-679.

20 Lurbe E, Cifkova R, Cruickshank JK, Dillon MJ, Ferreira I, Invitti C, Kuznetsova T, Laurent S, Mancia G, Morales-Olivas F, Rascher W, Redon J, Schaefer F, Seeman T, Stergiou G, Wuhl E, Zanchetti A. Management of high blood pressure in children and adolescents: recommendations of the European Society of Hypertension. J Hypertens 2009; 27: 1719-1742.

21 Urbina E, Alpert B, Flynn J, Hayman L, Harshfield GA, Jacobson M, Mahoney L, McCrindle B, Mietus-Snyder M, Steinberger J, Daniels S, American Heart Association Atherosclerosis Hypertension Obesity in Youth Committee. Ambulatory blood pressure monitoring in children and adolescents: recommendations for standard assessment: a scientific statement from the American Heart Association Atherosclerosis, Hypertension, and Obesity in Youth Committee of the council on cardiovascular disease in the young and the council for high blood pressure research. Hypertension 2008; 52: 433-451.

22 Bos WJ, Verrij E, Vincent HH, Westerhof BE, Parati G, van Montfrans GA. How to assess mean blood pressure properly at the brachial artery level. J Hypertens 2007; 25: 751-755.

23 Gavish B, Ben-Dov IZ, Bursztyn M. Linear relationship between systolic and diastolic blood pressure monitored over $24 \mathrm{~h}$ : assessment and correlates. J Hypertens 2008; 26: 199-209.

24 Devereux RB, Alonso DR, Lutas EM, Gottlieb GJ, Campo E, Sachs I, Reichek N. Echocardiographic assessment of left ventricular hypertrophy: comparison to necropsy findings. Am J Cardiol 1986; 57: 450-458.

25 de Simone G, Daniels SR, Devereux RB, Meyer RA, Roman MJ, de Divitiis O, Alderman $\mathrm{MH}$. Left ventricular mass and body size in normotensive children and adults: assessment of allometric relations and impact of overweight. J Am Coll Cardiol 1992; 20: 1251-1260.

26 Protogerou AD, Blacher J, Stergiou GS, Achimastos A, Safar ME. Blood pressure response under chronic antihypertensive drug therapy: the role of aortic stiffness in the
REASON (Preterax in Regression of Arterial Stiffness in a Controlled Double-Blind) study. J Am Coll Cardiol 2009; 53: 445-451.

27 Stella A, Gessaroli M, Cifiello BI, Salardi S, Reggiani A, Cacciari E, D'Addato M. Elastic modulus in young diabetic patients (ultrasound measurements of pulse wave velocity). Angiology 1984; 35: 729-734.

28 Woolam GL, Schnur PL, Vallbona C, Hoff HE. The pulse wave velocity as an early indicator of atherosclerosis in diabetic subjects. Circulation 1962; 25: 533-539.

29 Tedesco MA, Di Salvo G, Ratti G, Natale F, Calabrese E, Grassia C, lacono A, Lama G. Arterial distensibility and ambulatory blood pressure monitoring in young patients with neurofibromatosis type 1. Am J Hypertens 2001; 14: 559-566.

30 Kwok KL, Ng DK, Cheung YF. BP and arterial distensibility in children with primary snoring. Chest 2003; 123: 1561-1566.

31 Cheung YF, Yung TC, Tam SC, Ho MH, Chau AK. Novel and traditional cardiovascular risk factors in children after Kawasaki disease: implications for premature atherosclerosis. J Am Coll Cardiol 2004; 43: 120-124.

32 Cheung YF, Brogan PA, Pilla CB, Dillon MJ, Redington AN. Arterial distensibility in children and teenagers: normal evolution and the effect of childhood vasculitis. Arch Dis Child 2002; 87: 348-351.

33 de Divitiis M, Pilla C, Kattenhorn M, Donald A, Zadinello M, Wallace S, Redington A, Deanfield J. Ambulatory blood pressure, left ventricular mass, and conduit artery function late after successful repair of coarctation of the aorta. I Am Coll Cardiol 2003; 41: 2259-2265.

34 Collins RT, Somes GW, Alpert BS. Differences in arterial compliance among normotensive adolescent groups: Collins arterial compliance in adolescents. Pediatr Cardiol 2008; 29: 929-934.

35 Niboshi A, Hamaoka K, Sakata K, Inoue F. Characteristics of brachial-ankle pulse wave velocity in Japanese children. Eur J Pediatr 2006; 165: 625-629.

36 Im JA, Lee JW, Shim JY, Lee HR, Lee DC. Association between brachial-ankle pulse wave velocity and cardiovascular risk factors in healthy adolescents. J Pediatr 2007; 150: 247-251.

37 Sakuragi S, Abhayaratna K, Gravenmaker KJ, O'Reilly C, Srikusalanukul W, Budge MM, Telford RD, Abhayaratna WP. Influence of adiposity and physical activity on arterial stiffness in healthy children: the lifestyle of our kids study. Hypertension 2009; 53: 611-616.

38 Stergiou GS, Efstathiou SP, Argyraki CK, Gantzarou AP, Roussias LG, Mountokalakis TD. Clinic, home and ambulatory pulse pressure: comparison and reproducibility. $J$ Hypertens 2002; 20: 1987-1993.

39 Schillaci G, Parati G, Pirro M, Pucci G, Mannarino MR, Sperandini L, Mannarino E. Ambulatory arterial stiffness index is not a specific marker of reduced arterial compliance. Hypertension 2007; 49: 986-991.

40 Jerrard-Dunne P, Mahmud A, Feely J. Ambulatory arterial stiffness index, pulse wave velocity and augmentation index-interchangeable or mutually exclusive measures? J Hypertens 2008; 26: 529-534.

41 Muxfeldt ES, Fiszman R, Castelpoggi CH, Salles GF. Ambulatory arterial stiffness index or pulse pressure: which correlates better with arterial stiffness in resistant hypertension? Hypertens Res 2008; 1: 607-613.

42 Laugesen E, Hansen KW, Knudsen ST, Erlandsen M, Ebbehoj E, Mogensen CE, Poulsen PL. Increased ambulatory arterial stiffness index and pulse pressure in microalbuminuric patients with type 1 diabetes. Am J Hypertens 2009; 22: 513-519.

43 Adiyaman A, Boggia J, Li Y, Wang J-G, O'Brien E, Richart T, Thijs L, Staessen JA. Dipping deeper into the ambulatory arterial stiffness index. Hypertension 2007; 50: e59-e60.

44 Schillaci G, Parati G, Pirro M, Pucci G, Mannarino MR, Sperandini L, Mannarino E. Response to dipping deeper into the ambulatory arterial stiffness index. Hypertension 2007; 50: e61-e62.

45 Laurent S. Surrogate measures of arterial stiffness: do they have additive predictive value or are they only surrogates of a surrogate? Hypertension 2006; 47: 325-326.

46 Stergiou GS, Kollias A, Rarra VC, Roussias LG. Ambulatory arterial stiffness index: reproducibility of different definitions. Am J Hypertens 2010; 23: 129-134.

47 Lurbe E, Aguilar F, Gomez A, Tacons J, Alvarez V, Redon J. Reproducibility of ambulatory blood pressure monitoring in children. J Hypertens Supp/ 1993; 11: S288-S289.

48 Lurbe E, Thijs L, Redón J, Alvarez V, Tacons J, Staessen J. Diurnal blood pressure curve in children and adolescents. J Hypertens 1996; 14: 41-46.

49 Stergiou GS, Alamara CV, Salgami EV, Vaindirlis IN, Dacou-Voutetakis C, Mountokalakis TD. Reproducibility of home and ambulatory blood pressure in children and adolescents. Blood Press Monit 2005; 10: 143-147. 